\title{
Online Teaching Best Practices: Faculty Preferences
}

\section{Dr. Agnes Galambosi, UNCC}

Agnes Galambosi earned her PhD in Systems and Industrial Engineering from the University of Arizona in Tucson. She also holds two MS degrees: one in Systems Engineering from the University of Arizona in Tucson, one in Meteorology from Eotvos Lorand University in Budapest, Hungary. She currently teaches at Systems Engineering and Engineering Management program at the University of North Carolina at Charlotte. Her research interests include a wide range of topics from educational games in college teaching to engineering management and optimization problems and applying systems methods to climate change modelling.

\section{Dr. Ertunga C Ozelkan, University of North Carolina, Charlotte}

Ertunga C. Ozelkan, Ph.D., is Director and Associate Professor of Systems Engineering \& Engineering Management, and the Associate Director of the Center for Lean Logistics and Engineered Systems at the University of North Carolina at Charlotte. Before joining academia, Dr. Ozelkan worked for i2 Technologies, a leading supply chain software vendor and for Tefen USA, a systems design and industrial engineering consulting firm. Dr. Ozelkan holds a Ph.D. degree in Systems and Industrial Engineering from the University of Arizona. He teaches courses on supply chain management, lean systems, decision analysis, designed experimentation, and systems design and optimization. His current research interests include on the education side development of simulations and cases for active learning, and on the modeling side supply chains and logistics management, and production systems planning and optimization, and applications in different industries. 


\title{
Online Teaching Best Practices: Faculty Preferences
}

\begin{abstract}
Online education is a strategic initiative that has been applied for growth by a number of universities over the past decade. Establishing a quality online program, however, is easier said than done. The online learning system and infrastructure needs to be carefully designed to address not only the end-customers' (i.e., the students') needs but another important stakeholder's needs as well: the needs of the faculty who plays a major role executing the online production and delivery process. In this study, we analyze faculty preferences towards online teaching practices and related tools/techniques by investigating the differences with respect to factors like faculty demographics such as gender, age, as well as their job title (tenure status: tenure, tenure-track or non-tenure, status: full-time or part-time), the level of the course they teach and previous online teaching experiences. Best online teaching practices are being discussed in terms of ways of delivering the lectures, assignments, examinations, communication, class initiation, and attendance and participation requirements. These questions have been investigated via a survey conducted at University of North Carolina at Charlotte (UNC Charlotte). Based on the survey, faculty and student challenges with online teaching and faculty perception of ideal online-teaching environment are also discussed. The results show that there are some variations among these factors mentioned above.
\end{abstract}

\section{Introduction}

\section{Motivation:}

As distance education becomes more widespread, the benefits of distance education are very clear: in addition to flexibility and accessibility, it also offers no capacity constraints for the classroom in the traditional sense such as class size. As it has been previously discussed in Ozelkan and Galambosi ${ }^{[1,2]}$, distance education can also have a significant effect on increasing not only enrollment but the number of degrees completed as well, so it can be a very important strategy to grow a degree program.

Colleges at the UNC Charlotte, such as College of Arts and Architecture, Computing and Informatics, Education, Engineering, Health and Human Services and Liberal Arts and Sciences all are offering now online courses and online programs that started in recent years. The Systems Engineering and Engineering Management (SEEM) Program has also started its distance education courses during the Fall of 2009.

\section{Scope:}

This is a continuation of a previously presented work ${ }^{[1,2]}$ that analyzed general patterns for faculty preferences of online teaching methods such as synchronous, asynchronous versus mixed methods, based on their departments, demographics such as gender, age, as well as their job title (tenure status: tenure, tenure-track or non-tenure, status: full-time or part-time), the level of the course they teach and previous online teaching experiences. This study is a further extension of this analysis investigating best practices (such as ways of delivering the lectures, assignments, 
examinations, communication, class initiation, attendance and participation requirements) with respect to these same factors.

The purpose of the current paper is to answer the following two research questions: 1 . Is there a difference in the best online teaching practices based on faculty demographics? and 2 . What are the best practices used in online teaching? These research questions are addressed via a survey conducted at the UNC Charlotte among the online teaching faculty, and the results of this survey are analyzed and presented here.

\section{Literature Review:}

As the demand increases towards global online programs and courses, many guidelines and papers have been published on how to efficiently create an online learning environment (see e.g. Bender ${ }^{[3]}$ ). Since our previous work contains a detailed literature review (Ozelkan and Galambosi $^{[1,2]}$ ) here we refer to that. In addition, different aspects of online learning are mentioned in the following few articles. For example, Vonderwell, Lian and Alderman ${ }^{[4]}$ analyze the role of asynchronous discussion and assessment in online learning in five Master's level online courses. They have identified the following components as important in student learning: structure, learning community, self-regulatory cognitions, learner autonomy, student writing skills. They also carefully distinguish between "assessment for learning” and "assessment of learning”. Along the same lines, Gilbert and Dabbagh ${ }^{[5]}$ have also identified earlier that the instructors can enhance the learning experience by posting facilitator guidelines, evaluation rubrics and posting protocol items to lead to a more meaningful discourse and to lead to a deeper understanding of the material. Another aspect, how to effectively engage learners from diverse cultural backgrounds, is discussed by Wang ${ }^{[6]}$. Online learning environments might bring together students from diverse backgrounds, so this aspect might become more important as the online classrooms become more accessible worldwide through some global outreach programs. Their findings showed a high level of self-motivation in all students. They also found that asynchronous tools were preferred to synchronous methods in all groups but while American students had no problem communicating, Korean students were most hindered by online communication and Chinese students liked online broadcast with no interaction to be the best way of online learning. These findings can help the instructors fine tune their online classroom teaching methods if they know their target audience. Gahungu et al. ${ }^{[7]}$ analyzed a survey of 24 web-based course instructors about their online communication experiences. They have concluded while communication was easy in an online environment, there might be a need for tutorials for students on how to use online tools, and what the rules of online communication are. On the other hand, instructors should also receive orientation to strategies of online teaching. In addition, we would like to summarize the findings of Dennen et al. ${ }^{[8]}$ as they suggest the following for instructors to adopt best practices: 1 . instructors need to reply questions and give feedback in a timely manner; 2 . instructors need to show that they are present in the online classrooms on a regular basis; 3. instructors need to communicate their expectations clearly. We aim to come up with some similar findings and insights based on the survey conducted.

The rest of the paper is organized as follows: after a brief description of the survey study in the next section, related analysis is presented. The final section summarizes the main findings of our analysis. 


\section{Survey Analysis}

An online faculty survey was conducted at UNC Charlotte. The university has currently 118 faculty members teaching online courses in six colleges: Arts \& Architecture, Computing \& Informatics, Education, Engineering, Health \& Human Services, and Liberal Arts \& Sciences. 62 of them replied to the survey yielding a $53 \%$ response rate. Based on the survey results, the demographics of the participating faculty indicate that the majority of the respondents were female (67\%), ages 41-50 (33\%), dominantly Caucasian (90\%), mostly from the College of Education (37\%), (while Engineering faculty was 15\% of the respondents), most of them work full-time (62\%), most are tenure-track or tenured (58\%), and most are Assistant Professors (26\%) and Associate Professors (24\%).

For this survey, it was highlighted that traditional or On-Campus courses that use support tools such as Moodle/WebCT/Blackboard solely for posting materials or announcements for the oncampus students were not considered as “online” learning here.

The best practices discussed here can be categorized as lecture delivery, assignments/exams, communication, starting a class, and tracking online activities are summarized in Table 1. Lecture delivery category included posting detailed lecture notes, posting presentation slides, posting lecture presentation with voice over, posting pre-recorded lecture video, delivering live lectures online with audio only, delivering live lectures online with video, posting other academic/industrial/commercial videos e.g. software demos, and industry best practice videos. Assignments/examinations category included lecture discussion questions, homework assignments, term project, live-synchronous project or assignment presentations, online quizzes, take-home exams, and proctored exams. Communication category included email, phone, online chat, Q/A discussion forums, surveys, calendar of events. Starting a class category included self introductions and confirming understanding of syllabus, and finally tracking of online activities included tracking of detailed online presence of the students as logged in the learning management system. 


\begin{tabular}{|c|c|}
\hline Best Practice Category & Techniques/Best Practices \\
\hline \multirow[t]{7}{*}{ Lecture Delivery } & Slides \\
\hline & Industry Videos \\
\hline & Notes \\
\hline & Rec Audio Lecture \\
\hline & Live lecture w/Video \\
\hline & Rec Video Lecture \\
\hline & Live lecture w/Audio \\
\hline \multirow[t]{7}{*}{ Assignments/Exams } & HW \\
\hline & DQs \\
\hline & Project \\
\hline & Quiz \\
\hline & Take-Home \\
\hline & Live project presentation \\
\hline & Proctored \\
\hline \multirow[t]{6}{*}{ Communication } & Emails \\
\hline & Calendar \\
\hline & $\mathrm{Q} / \mathrm{A}$ Forum \\
\hline & Chat \\
\hline & Survey \\
\hline & $\mathrm{Ph}$ \\
\hline \multirow[t]{2}{*}{ Starting a class } & Confirm Syllabus \\
\hline & Self Intro \\
\hline Tracking Online Activities & Tracking \\
\hline
\end{tabular}

Table 1. Best Practices Surveyed

Figure 1 shows the results for the rating of online teaching best practices for different colleges. The pattern in general seems to be that all colleges have a similar preference toward these methods with the exception of Arts and Architecture. For example, confirming the syllabus is the highest used practice in all colleges but for the College of Arts and Architecture it is not the highest, it is average rated. Other highly preferred practices also include emails, tracking, homework assignments (HWs), discussion questions (DQs) and self-introduction (but this one is not popular in the College of Arts and Architecture). On the other hand, the least used practices in general are live or recorded video lectures, both with video and audio. Proctored exams are also preferred in Arts and Architecture and Computing and Informatics but other colleges actually rated them average at best. It also has to be mentioned that the response for both of these colleges is the lowest, only 2 people in each of these colleges, so caution needs to be practiced to make these conclusions. Not taking into consideration these two colleges, in terms of the best practice for the delivery of the lectures, slides are the most preferred way regardless of the college, except in Engineering, where industry videos ranked higher. Live lectures with audio are the least preferred way for Engineering and Health and Humanities but for Education and Liberal Arts and Sciences it is the recorded video lecture. In terms of assignments/exams, homeworks 
and discussion questions seem to be all important for all colleges, while proctored exams are the least preferred for all colleges. In terms of communication and starting a class, all colleges agree that confirming the syllabus is crucial and email communication is the best practice. All colleges value high the tracking of attendance and participation.

\begin{tabular}{|c|c|c|c|c|c|c|c|}
\hline Techniques & 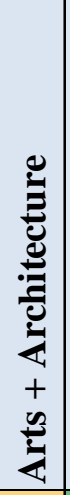 & 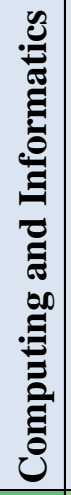 & 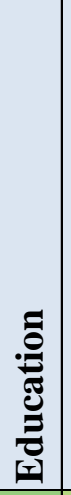 & 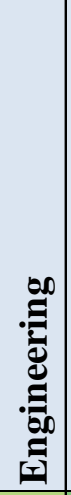 & 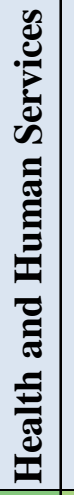 & 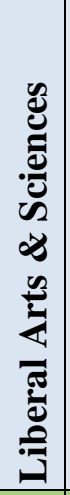 & 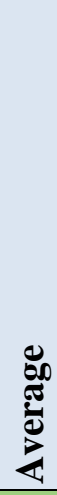 \\
\hline Confirm Syllabus & 3.5 & 5.0 & 4.7 & 4.4 & 4.8 & 4.5 & 4.6 \\
\hline Emails & 5.0 & 5.0 & 4.7 & 3.9 & 4.7 & 4.4 & 4.5 \\
\hline Tracking & 5.0 & 5.0 & 4.7 & 4.0 & 4.8 & 4.3 & 4.5 \\
\hline Self Intro & 3.0 & 5.0 & 4.6 & 4.2 & 4.8 & 4.1 & 4.4 \\
\hline $\mathrm{HW}$ & 4.5 & 5.0 & 4.4 & 4.3 & 4.3 & 4.3 & 4.4 \\
\hline DQs & 4.5 & 5.0 & 4.3 & 4.3 & 4.3 & 4.3 & 4.4 \\
\hline Calendar & 4.5 & 5.0 & 4.4 & 3.6 & 4.5 & 4.1 & 4.3 \\
\hline $\mathrm{Q} / \mathrm{A}$ Forum & 4.5 & 5.0 & 4.3 & 3.9 & 4.5 & 3.8 & 4.2 \\
\hline Slides & 4.0 & 4.0 & 4.3 & 3.7 & 4.3 & 3.9 & 4.1 \\
\hline Project & 3.5 & 5.0 & 4.1 & 4.2 & 4.1 & 3.8 & 4.1 \\
\hline Quiz & 5.0 & 4.0 & 3.8 & 3.7 & 3.8 & 4.4 & 3.9 \\
\hline Industry Videos & 5.0 & 4.5 & 4.0 & 4.0 & 3.9 & 3.3 & 3.9 \\
\hline Chat & 3.5 & 4.5 & 4.0 & 3.3 & 3.5 & 4.0 & 3.8 \\
\hline Notes & 4.0 & 5.0 & 3.5 & 3.6 & 3.9 & 3.9 & 3.8 \\
\hline Survey & 4.5 & 5.0 & 3.7 & 3.2 & 2.8 & 3.4 & 3.5 \\
\hline Rec Audio Lecture & 2.5 & 2.5 & 3.6 & 3.7 & 3.7 & 3.1 & 3.5 \\
\hline Take-Home & 5.0 & 4.0 & 3.4 & 3.7 & 2.6 & 3.8 & 3.4 \\
\hline $\mathrm{Ph}$ & 3.5 & 3.5 & 3.6 & 3.2 & 3.6 & 3.0 & 3.4 \\
\hline Live project presentation & 1.5 & 2.0 & 3.7 & 3.6 & 2.5 & 2.8 & 3.1 \\
\hline live lecture w/Video & 1.5 & 2.0 & 3.2 & 3.4 & 2.8 & 2.9 & 3.0 \\
\hline Rec Video Lecture & 2.5 & 2.5 & 2.8 & 3.6 & 3.3 & 2.7 & 3.0 \\
\hline Live lecture w/Audio & 1.5 & 2.5 & 3.0 & 2.7 & 2.8 & 2.9 & 2.8 \\
\hline Proctored & 4.0 & 4.0 & 2.6 & 2.7 & 2.8 & 2.9 & 2.8 \\
\hline Number of responses & 2 & 2 & 23 & 9 & 13 & 13 & 62 \\
\hline
\end{tabular}

Figure 1. Rating of Online Teaching Best Practices for Different Colleges.

Figure 2 shows the results for the rating of online teaching best practices based on gender. In general, looking at the overall picture, confirming the syllabus, emails, tracking are preferred the 
most. While both female and male preferences follow a similar pattern, in general, females seem to rate online techniques higher than males, except for the rating of take-home exams. Another observation that can be made is that females tend to have a lightly larger range between the most and least liked best practices (between 2.9 and 4.8) compared to males (between 2.7 to 4.3 ).

In terms of the best practice for the delivery of the lectures, slides are the most preferred way, regardless of gender, while live lectures with audio are the least preferred way for both genders. The most important in the assignments/exams category are the same for both males and females: homeworks and discussion questions, while the least important one is proctored exams, regardless of gender. In terms of communication and starting a class, the genders agree that confirming the syllabus is crucial and email communication is the best practice. Both also value high the tracking of attendance and participation.

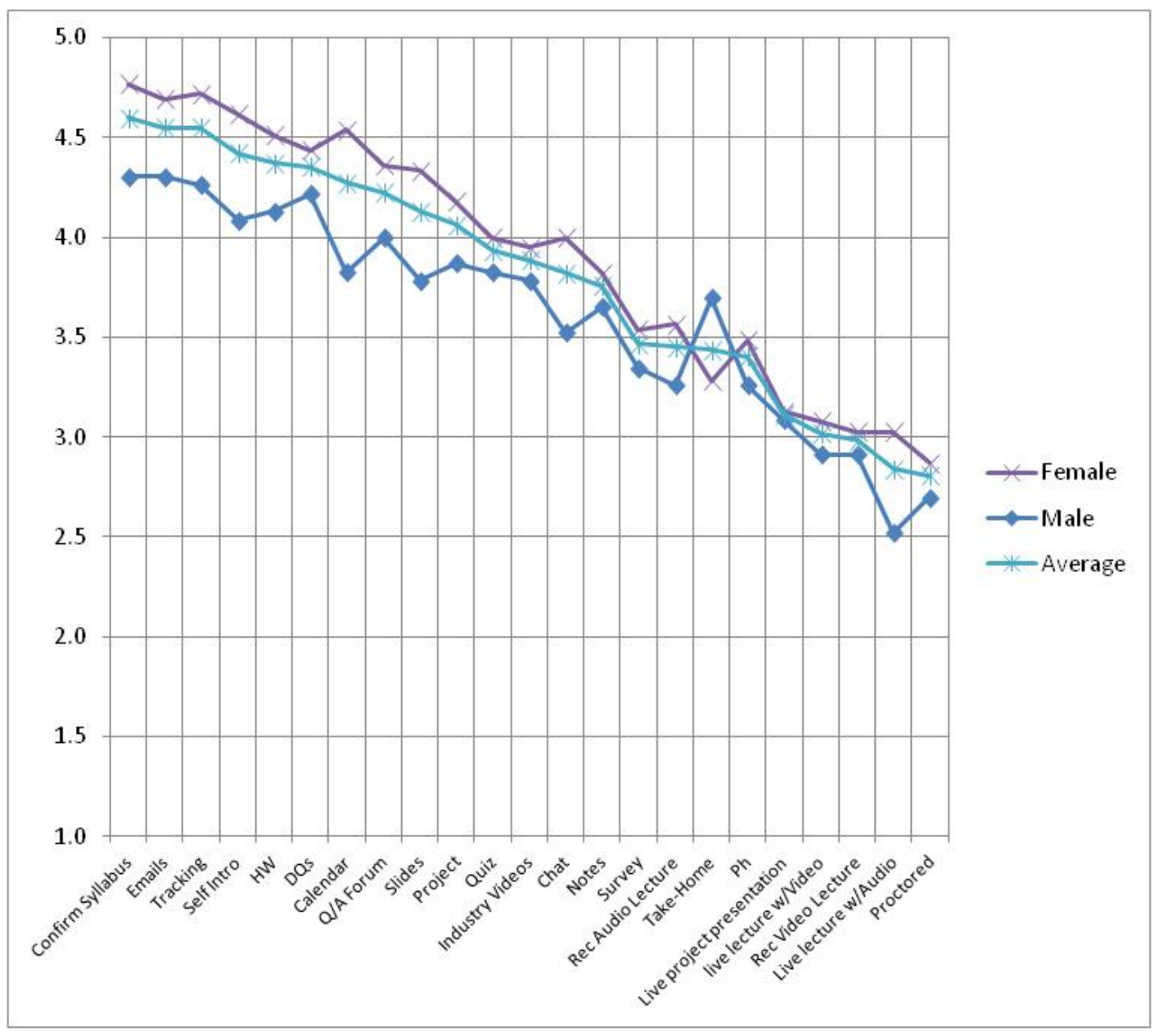

Figure 2. Rating of Online Teaching Best Practices based on Gender.

Figure 3 shows the ratings of online teaching best practices based on age. Please note that the age group "below 30" has been omitted here due to having only one response in that category. While it may seem unrealistic to completely eliminate that category from the analysis, the authors decided that no valid generalization and conclusion can be drawn from a sample size of one in a 
category. There seems to be a consensus about the majority of the best practices across the age groups: just like across colleges, the most valued practices are: confirm syllabus, emails, tracking, self-introduction, HW, DQs. The age group 51-60 seems to be the interested in projects and less interested than other age groups in notes. While the pattern for most commonly used best practices seems to be not very expressed between the age groups, the differences between the least used practices seems to be bigger among the age categories. For example, the lowest overall score was given in the $>60$ category for proctored exams (score of 2.3) but the lowest score in the 51-60 category are for live project presentation and also live lecture with audio (both with a score of 3.1).

The best practice for the delivery of the lectures seems to be slides, regardless of the age. Live lectures with audio are the least preferred way for the age group 41-50 and 51-60 but the least preferred method is recorded video lecture for the 31-40 and >60 groups. For all ages, in the assignments/exams category homeworks and discussion questions seem to be very important, while proctored exams are the least preferred for all age groups. In terms of communication and starting a class, all ages agree that confirming the syllabus is crucial and email communication is the best practice. All age groups value high the tracking of attendance and participation.

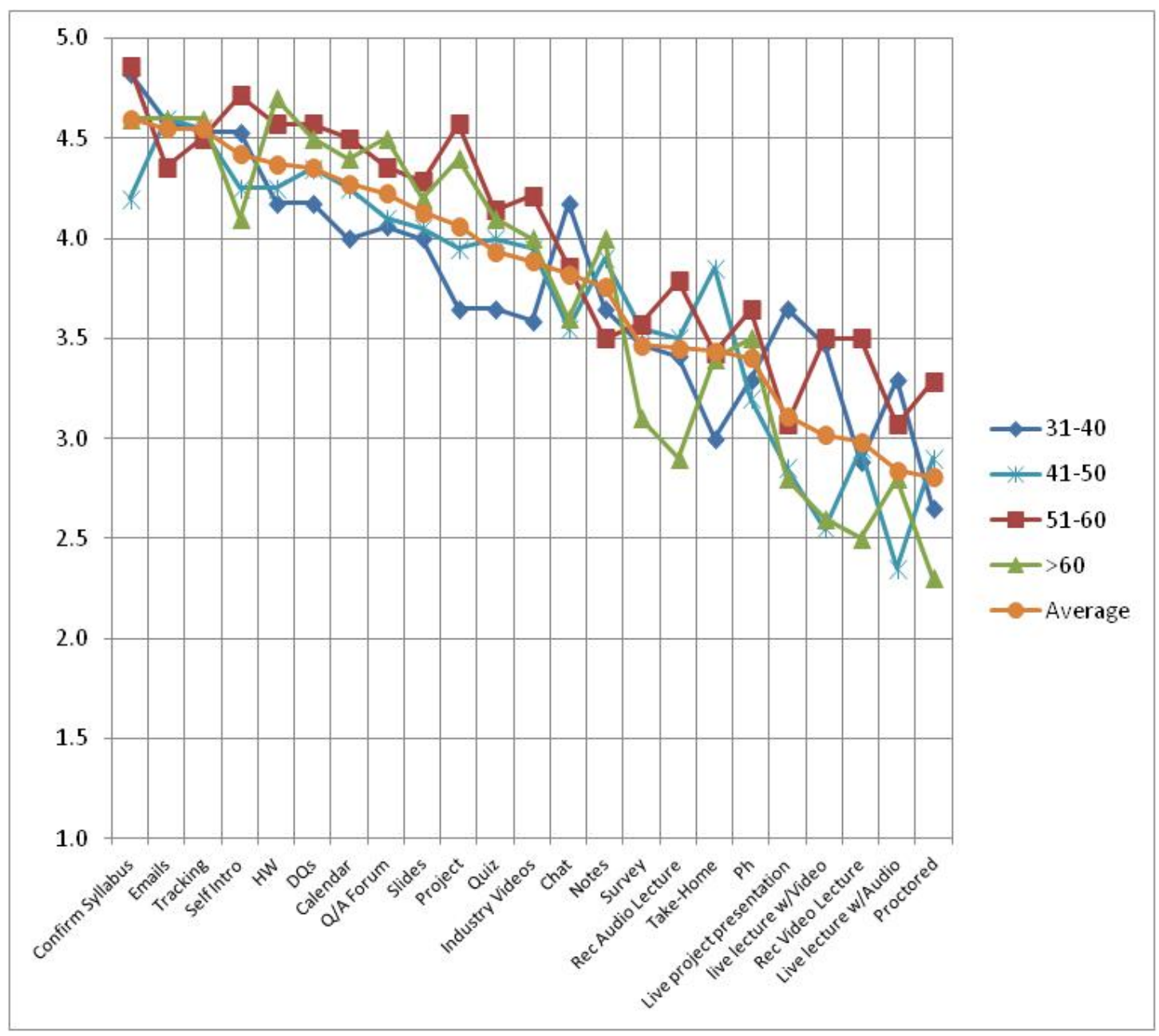

Figure 3. Rating of Online Teaching Best Practices based on Age. 
Figure 4 shows the rating of online teaching best practices based on full-time versus part-time employment. With 51 full-time and 11 part-time respondents, the average is dominated by what the full-timers prefer. The difference between the part-timers and full-timers is that part-time teachers consistently gave higher scores on the majority of these practices and part-time employees valued phone discussions much higher than their full-time counterparts (4.0 versus 3.3 , respectively).

The best practice for the delivery of the lectures seems to be slides, regardless of the employment level. Live lectures with video are the least preferred way for part-timers but it is live lectures with audio for the full-timers. For the assignments/exams category, homeworks and discussion questions seem to be very important regardless of employment, while proctored exams are the least preferred for both full-time and part-time instructors. In terms of communication and starting a class, both groups agree that confirming the syllabus is crucial and email communication is the best practice. Both groups also value high the tracking of attendance and participation.

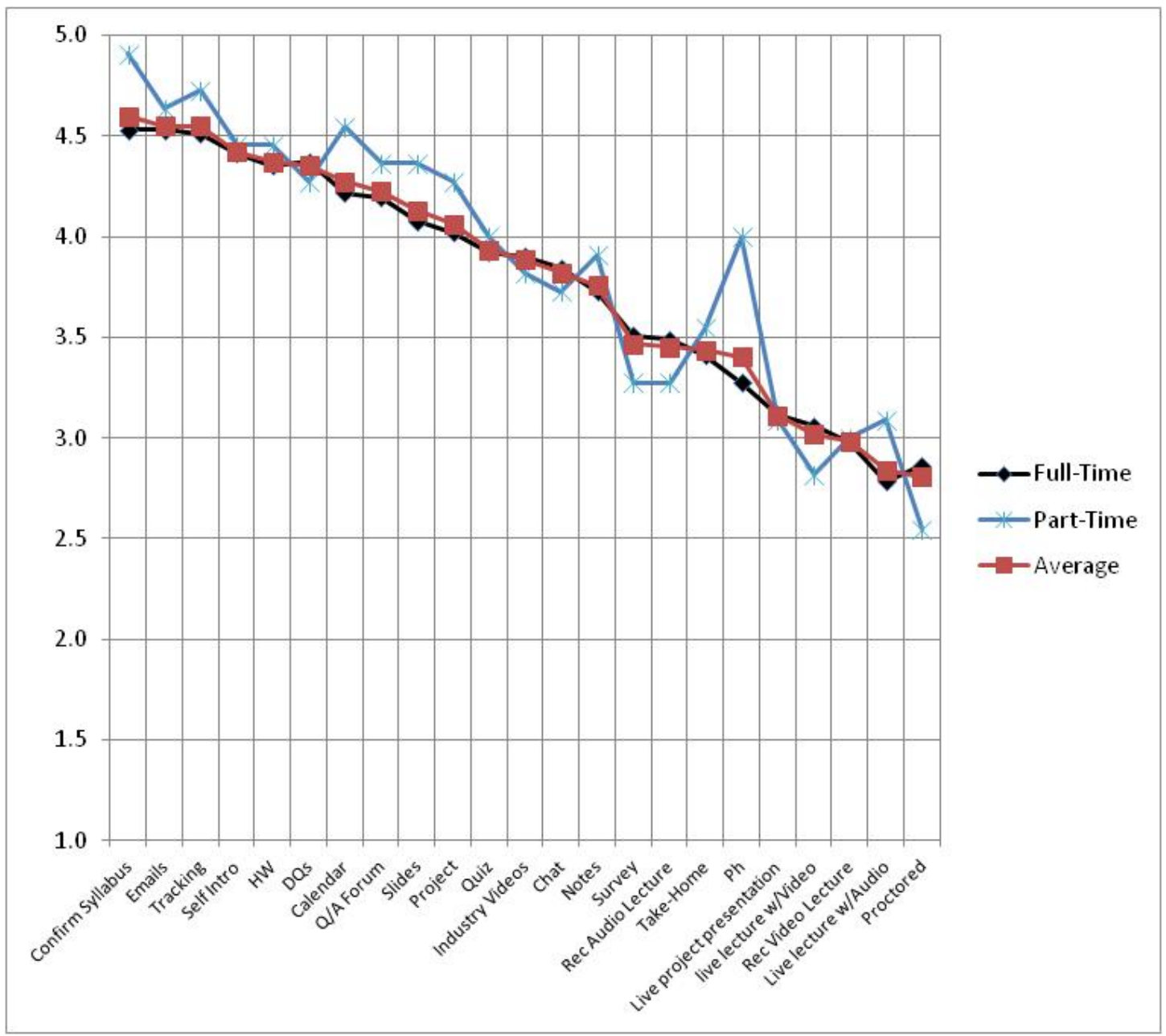

Figure 4. Rating of Online Teaching Best Practices based on Full vs. Part-time employment. 
Figure 5 shows the rating of online techniques based on tenure status. There doesn't seem to be a big difference in the three tenure status categories (non-tenure track, tenured, tenure-track). On the other hand, general trend shows that tenure-track faculty rate online practices higher than non-tenure track faculty. Lecture delivery using slides seems to be the best way for both nontenure track and tenured teachers, however, for tenure-track teachers the best way is industry videos. For the assignments/exams category, homeworks and discussion questions are important for all positions, and proctored exams are the least preferred for all tenure status. In terms of communication and starting a class, all levels of tenure status agree that confirming the syllabus is crucial and email communication is the best practice. All tenure groups value high tracking of attendance and participation.

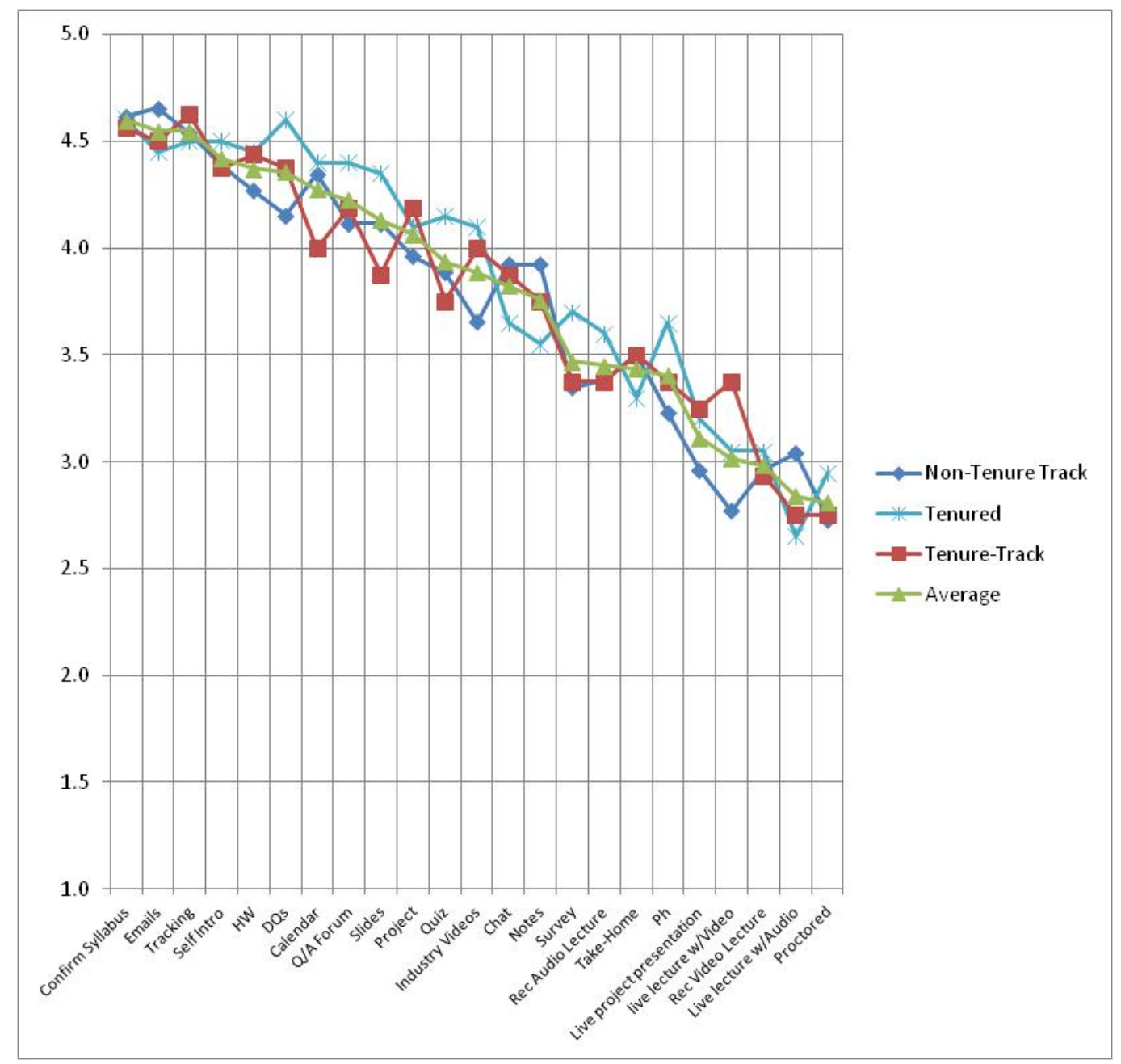

Figure 5. Rating of Online Teaching Best Practices based on Tenure Status.

Figure 6 shows the rating of online teaching best practices based on positions. Full-time lecturers seem to give lower scores than the others for the majority of these methods. Full time lecturers/instructors/faculty associates also seem to have a really strong preference for asynchronous methods. Lecture delivery using slides seems to be the best way for all but assistant professors, who prefer industry videos. In the assignments/exams category, homeworks 
and discussion questions are important for all positions, on the other hand, proctored exams are the least preferred method of assessment. In terms of communication and starting a class, all groups agree that confirming the syllabus is crucial and email communication is the best practice. All positions value high the tracking of attendance and participation. While the number of responses is only three, it is worth noting that the clinical assistant professors seem to prefer live (synchronous) lectures as opposed to recorded (asynchronous) lectures. These professors belong to the College of Education and deal with counseling, special education and child development, and K-12 education, which may explain the need for live real time interactions with the students.

\begin{tabular}{|c|c|c|c|c|c|c|c|}
\hline Techniques & 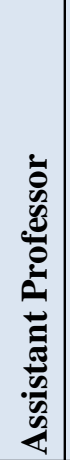 & 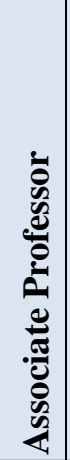 & 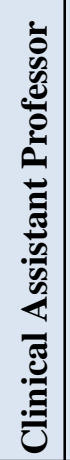 & 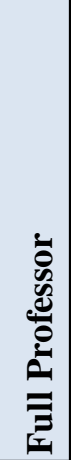 & 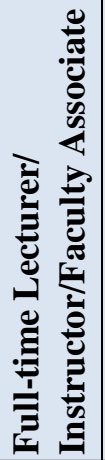 & 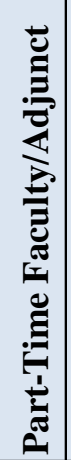 & 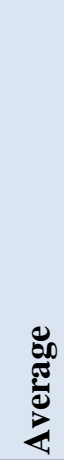 \\
\hline Confirm Syllabus & 4.6 & 4.6 & 4.7 & 4.6 & 4.4 & 5.0 & 4.6 \\
\hline Emails & 4.6 & 4.4 & 4.7 & 4.4 & 4.7 & 4.6 & 4.5 \\
\hline Tracking & 4.7 & 4.5 & 4.7 & 4.6 & 4.4 & 4.7 & 4.5 \\
\hline Self Intro & 4.5 & 4.4 & 4.7 & 4.6 & 4.3 & 4.3 & 4.4 \\
\hline \begin{tabular}{|l|}
$\mathrm{HW}$ \\
\end{tabular} & 4.5 & 4.5 & 4.3 & 4.4 & 4.1 & 4.3 & 4.4 \\
\hline DQs & 4.4 & 4.6 & 4.3 & 4.6 & 4.1 & 4.0 & 4.4 \\
\hline Calendar & 4.0 & 4.4 & 4.3 & 4.4 & 4.3 & 4.4 & 4.3 \\
\hline Q/A Forum & 4.2 & 4.5 & 4.0 & 4.1 & 4.1 & 4.1 & 4.2 \\
\hline Slides & 3.9 & 4.4 & 4.3 & 4.3 & 4.0 & 4.1 & 4.1 \\
\hline Project & 4.3 & 4.1 & 4.0 & 4.3 & 3.8 & 4.0 & 4.1 \\
\hline Quiz & 3.7 & 4.2 & 4.0 & 3.7 & 4.0 & 4.0 & 3.9 \\
\hline Industry Videos & 4.0 & 4.1 & 4.0 & 4.1 & 3.6 & 3.6 & 3.9 \\
\hline Chat & 3.9 & 3.5 & 4.3 & 3.9 & 3.9 & 3.9 & 3.8 \\
\hline Notes & 3.6 & 3.7 & 4.0 & 3.4 & 4.2 & 3.4 & 3.8 \\
\hline Survey & 3.2 & 3.9 & 4.0 & 3.0 & 3.4 & 3.7 & 3.5 \\
\hline Rec Audio Lecture & 3.4 & 3.3 & 2.7 & 4.0 & 3.5 & 3.6 & 3.5 \\
\hline Take-Home & 3.6 & 3.1 & 2.7 & 3.3 & 3.6 & 3.9 & 3.4 \\
\hline $\mathrm{Ph}$ & 3.3 & 3.6 & 3.3 & 3.9 & 2.9 & 4.0 & 3.4 \\
\hline Live project presentation & 3.2 & 3.2 & 3.7 & 3.1 & 2.6 & 3.6 & 3.1 \\
\hline live lecture w/Video & 3.3 & 3.0 & 3.0 & 3.1 & 2.6 & 3.0 & 3.0 \\
\hline Rec Video Lecture & 2.9 & 2.7 & 2.7 & 3.7 & 2.9 & 3.3 & 3.0 \\
\hline Live lecture w/Audio & 2.7 & 2.5 & 4.0 & 3.0 & 2.7 & 3.4 & 2.8 \\
\hline \begin{tabular}{|l|} 
Proctored \\
\end{tabular} & 2.8 & 2.7 & 2.3 & 3.1 & 2.8 & 2.9 & 2.8 \\
\hline Number of responses & 16 & 15 & 3 & 7 & 13 & 7 & 62 \\
\hline
\end{tabular}

Figure 6. Rating of Online Teaching Best Practices based on Position. 
Figure 7 illustrates the rating of online teaching best practices based on previous participation in an online class as a student. More specifically, the preference is strong for best practices such as confirm syllabus, emails, tracking, self introduction, HW, DQs, calendar and Q/A forum if they have participated in an online class before. Those faculty who took an online class, seem to also value more the audio lecture recording while not prefer take home exams. The best practice for the delivery of the lectures seems to be slides, regardless of having taken an online class earlier. For assignments/exams, homeworks and discussion questions seem to be very important but proctored exams are the least preferred for both groups. In terms of communication and starting a class, the groups agree that confirming the syllabus is crucial and email communication is the best practice. They also all value high tracking of attendance and participation.

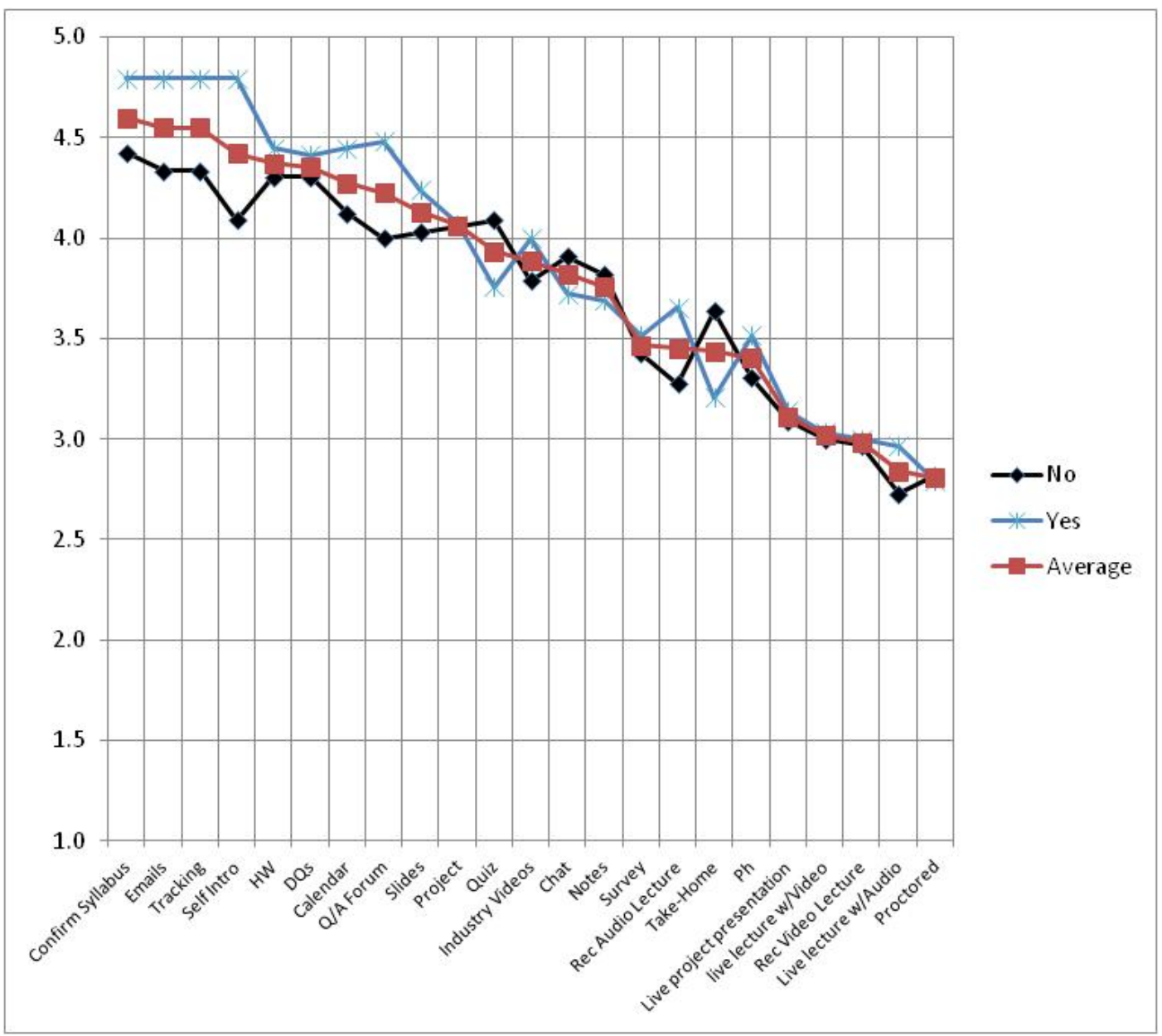

Figure 7. Rating of Online Teaching Best Practices based on Previous Participation in an Online Class.

Figure 8 is about the rating of online teaching best practices based on online teaching experience. The lowest scores are given from the more than 10 years group for take home exams (1.7) and live project presentation (2.0) as well as for recorded video lecture and live video lecture with audio from the 5-6 year experience group (both 2.0), One of the highest scores is also given by the more than 10 years group (5.0) for confirming syllabus, tracking, self-intro and Q/A forum. This seems to be aligned with the general pattern, however, the authors would like to note to 
exercise caution when coming up with conclusions about these categories as both of these categories have only 2 or 3 responses in them. A general pattern seems to be that the more experience, the higher the scores given for the best practices but this pattern has a few exceptions. Lecture delivery using slides seems to be the best way for all groups, although industry videos are also equally important for teachers with experience of 1-2 years. For assignments/exams, homeworks and discussion questions are important for all experience levels and proctored exams are the least preferred for all experience levels. In terms of communication and starting a class, all experience levels agree that confirming the syllabus is crucial and email communication is the best practice. All groups value high the tracking of attendance and participation.

\begin{tabular}{|c|c|c|c|c|c|c|c|c|}
\hline Techniques & 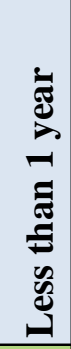 & 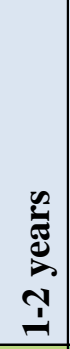 & 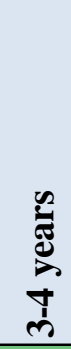 & 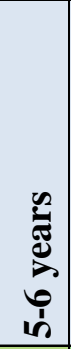 & 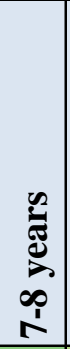 & 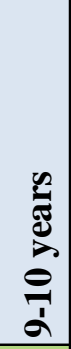 & 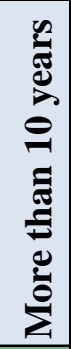 & 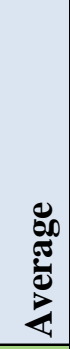 \\
\hline Confirm Syllabus & 4.5 & 4.4 & 4.9 & 4.5 & 4.8 & 4.5 & 5.0 & 4.6 \\
\hline Emails & 4.5 & 4.5 & 4.8 & 4.5 & 4.5 & 4.5 & 4.7 & 4.5 \\
\hline Tracking & 4.6 & 4.5 & 4.6 & 4.5 & 4.5 & 4.5 & 5.0 & 4.5 \\
\hline Self Intro & 4.3 & 4.1 & 4.9 & 4.5 & 5.0 & 4.2 & 5.0 & 4.4 \\
\hline HW & 4.4 & 4.4 & 4.5 & 4.0 & 4.3 & 4.3 & 4.3 & 4.4 \\
\hline DQs & 4.3 & 4.3 & 4.3 & 4.5 & 5.0 & 4.0 & 4.7 & 4.4 \\
\hline Calendar & 4.0 & 4.1 & 4.7 & 4.5 & 4.3 & 4.5 & 4.7 & 4.3 \\
\hline Q/A Forum & 3.8 & 4.1 & 4.5 & 4.5 & 4.8 & 4.0 & 5.0 & 4.2 \\
\hline Slides & 3.6 & 4.0 & 4.3 & 4.5 & 4.8 & 4.5 & 4.3 & 4.1 \\
\hline Project & 4.1 & 4.0 & 4.3 & 3.5 & 3.8 & 4.0 & 4.3 & 4.1 \\
\hline Quiz & 4.0 & 3.9 & 3.8 & 3.0 & 4.5 & 4.3 & 4.3 & 3.9 \\
\hline Industry Videos & 3.5 & 4.0 & 4.1 & 4.0 & 3.5 & 3.8 & 4.0 & 3.9 \\
\hline Chat & 3.9 & 3.7 & 4.0 & 4.0 & 3.8 & 3.8 & 3.7 & 3.8 \\
\hline Notes & 3.8 & 3.7 & 3.6 & 3.5 & 4.3 & 3.8 & 4.3 & 3.8 \\
\hline Survey & 3.3 & 3.4 & 3.4 & 3.5 & 4.0 & 4.0 & 3.3 & 3.5 \\
\hline Rec Audio Lecture & 3.0 & 3.4 & 3.6 & 4.5 & 3.0 & 4.2 & 3.3 & 3.5 \\
\hline Take-Home & 4.0 & 3.4 & 3.3 & 2.5 & 4.0 & 3.8 & 1.7 & 3.4 \\
\hline $\mathrm{Ph}$ & 3.6 & 3.0 & 3.8 & 3.5 & 4.0 & 3.3 & 4.0 & 3.4 \\
\hline Live project presentation & 3.5 & 3.1 & 3.1 & 4.5 & 3.3 & 2.8 & 2.0 & 3.1 \\
\hline live lecture w/Video & 3.0 & 2.8 & 3.2 & 3.5 & 3.5 & 3.0 & 3.3 & 3.0 \\
\hline Rec Video Lecture & 3.3 & 3.0 & 3.0 & 2.0 & 2.5 & 3.2 & 3.3 & 3.0 \\
\hline Live lecture w/Audio & 2.6 & 2.9 & 2.9 & 2.0 & 2.8 & 3.0 & 3.3 & 2.8 \\
\hline Proctored & 2.8 & 2.8 & 2.9 & 2.5 & 2.5 & 3.0 & 3.0 & 2.8 \\
\hline Number of responses & 8 & 27 & 12 & 2 & 4 & 6 & 3 & 62 \\
\hline
\end{tabular}

Figure 8. Rating of Online Teaching Best Practices based on Online Teaching Experience 
Figure 9 is about rating the online teaching best practices based on previous training online. It is true in general that having training makes the teachers give higher scores for all the best practices. The exception from this rule seems to be for notes and quizzes. While the most important practice for teachers with no previous training seems to be emails, for the trained teachers it is confirming syllabus. The top group of best practices shows the same methods: confirm syllabus, emails, tracking, self-introduction, HW, DQs, and there is also a similar consensus for the lest preferred methods: live project presentation, live lecture with video, recorded video lecture, live lecture with audio, and proctored exams. Lecture delivery using slides seems to be the best way for both groups. For assignments/exams, homeworks and discussion questions are important regardless of online training, while proctored exams are the least preferred for both groups. In terms of communication and starting a class, both groups agree that confirming the syllabus is crucial and email communication is the best practice. Both groups value high the tracking of attendance and participation.

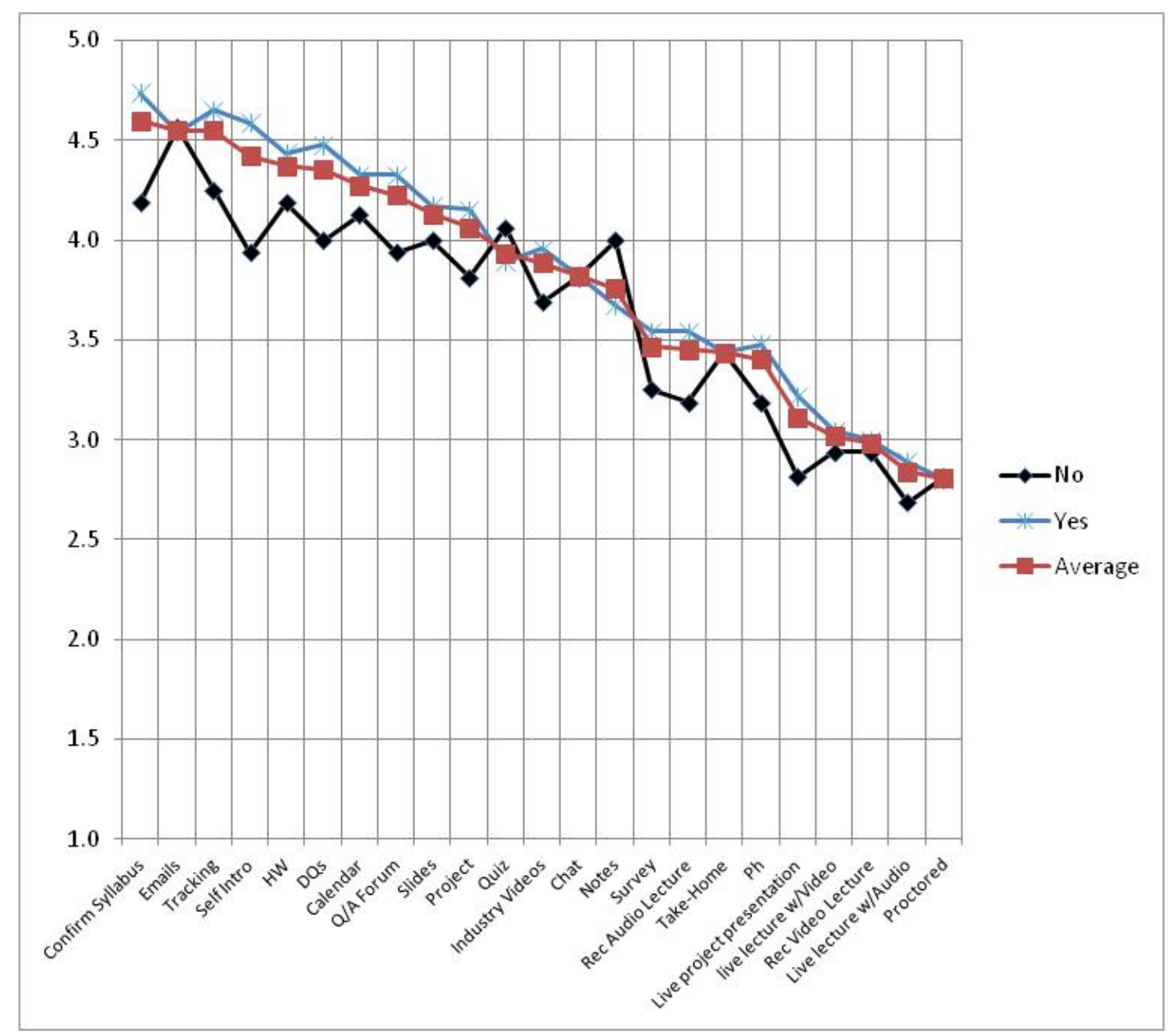

Figure 9. Rating of Online Teaching Best Practices based on Previous Training on Online Teaching. 
Figure 10 is rating of online teaching best practices based on online teaching proportion. Balanced teachers with both online and on campus teaching and mostly online teachers seem to have the highest scores for almost all of these methods. Mostly on campus teachers have the lowest preferences for most of these techniques but unlike all the other teachers, they really seem to like take home exams. Lecture delivery using slides seems to be the best way for all groups, although industry videos are a close second. In the assignments/exams category, homeworks and discussion questions are important regardless of online training, while proctored exams are the least preferred for all proportion status, although mostly online teachers also seem to equally dislike take home exams. In terms of communication and starting a class, all proportion status teachers agree that confirming the syllabus is crucial and email communication is the best practice. All groups value high the tracking of attendance and participation.

\begin{tabular}{|l|r|r|r|r|r|}
\hline Techniques & All online & Balanced & \multicolumn{1}{l|}{$\begin{array}{l}\text { Mostly } \\
\text { on-campus }\end{array}$} & $\begin{array}{l}\text { Mostly } \\
\text { online }\end{array}$ & Average \\
\hline Confirm Syllabus & 4.8 & 4.8 & 4.4 & 4.7 & 4.6 \\
\hline Emails & 4.7 & 4.5 & 4.4 & 4.8 & 4.5 \\
\hline Tracking & 4.5 & 4.7 & 4.5 & 4.7 & 4.5 \\
\hline Self Intro & 4.5 & 4.7 & 4.2 & 4.8 & 4.4 \\
\hline HW & 4.5 & 4.3 & 4.4 & 4.2 & 4.4 \\
\hline DQs & 4.3 & 4.4 & 4.4 & 4.3 & 4.4 \\
\hline Calendar & 4.3 & 4.5 & 4.1 & 4.5 & 4.3 \\
\hline Q/A Forum & 4.5 & 4.5 & 3.9 & 4.5 & 4.2 \\
\hline Slides & 4.3 & 4.3 & 4.0 & 4.2 & 4.1 \\
\hline Project & 3.9 & 4.1 & 4.1 & 4.0 & 4.1 \\
\hline Quiz & 3.8 & 3.9 & 4.1 & 3.3 & 3.9 \\
\hline Industry Videos & 3.6 & 4.2 & 3.9 & 3.7 & 3.9 \\
\hline Chat & 3.7 & 4.3 & 3.6 & 3.8 & 3.8 \\
\hline Notes & 3.8 & 3.1 & 4.0 & 4.2 & 3.8 \\
\hline Survey & 3.5 & 3.9 & 3.4 & 3.0 & 3.5 \\
\hline Rec Audio Lecture & 3.5 & 3.6 & 3.3 & 3.8 & 3.5 \\
\hline Take-Home & 3.2 & 3.1 & 3.9 & 2.7 & 3.4 \\
\hline Ph & 3.9 & 3.5 & 3.1 & 3.8 & 3.4 \\
\hline Live project presentation & 3.0 & 3.7 & 2.9 & 2.8 & 3.1 \\
\hline live lecture w/Video & 2.7 & 3.5 & 2.9 & 3.2 & 3.0 \\
\hline Rec Video Lecture & 2.7 & 2.9 & 3.1 & 3.2 & 3.0 \\
\hline Live lecture w/Audio & 2.8 & 3.0 & 2.7 & 3.0 & 2.8 \\
\hline Proctored & 2.6 & 3.0 & 2.8 & 2.7 & 2.8 \\
\hline
\end{tabular}

Figure 10. Rating of Online Teaching Best Practices based on Online Teaching Portion.

Figure 11 shows rating of online teaching best practices based on online teaching level of the courses. Graduate classes seem to have higher values for almost all the categories than teachers of undergraduate or both graduate and undergraduate classes. Two exceptions of this rule are 
quizzes (these seems to be more important in undergraduate classes than in graduate classes), and proctored exams (they are lower rated by graduate teaching instructors than undergraduate teaching only).

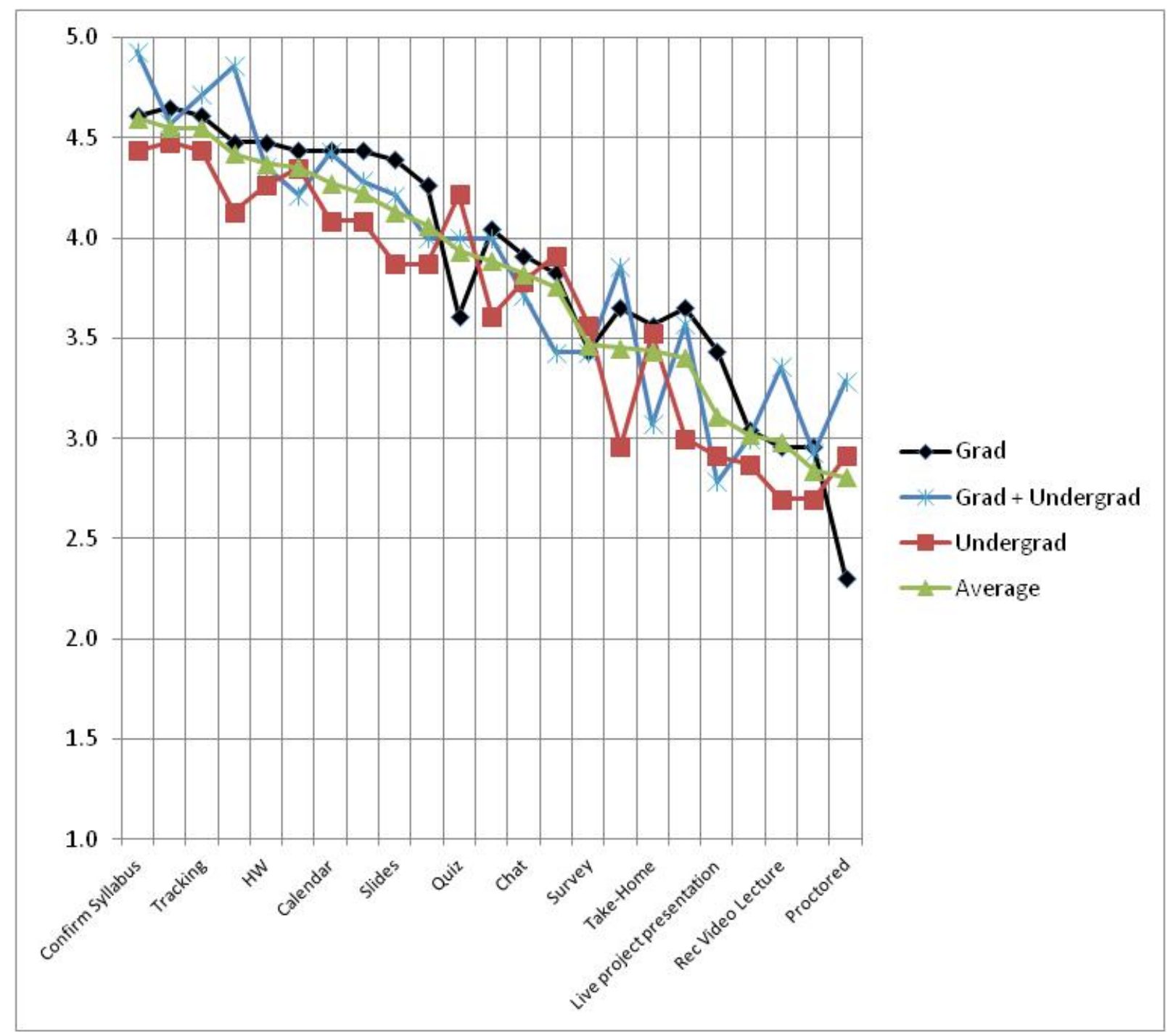

Figure 11. Rating of Online Teaching Best Practices based on Online Teaching Level.

In addition, an open-ended question was also asked about the faculty best practices: "What other practices/tools you would recommend utilizing for the success of your online teaching?”'These suggestions are grouped below.

Tips for best practices:

- weekly assignments should have answers posted the following week, after grading

- grouping students for discussions in large classes, have small-group discussions online

- use the news forum to present each module and explain misunderstandings

- respond to questions quickly

- modify the modules or deadlines quickly when the need arises, so be considerate of the students' issues 
- have some pre-class web discussion that prompts online discussion

To improve the learning material:

- making the syllabus and assignment information as clear as possible

- make the style of assignments and formats the same from week to week to make the logistics of the assignment easy

- post engaging material on Moodle (e.g. cartoons, animations, etc.)

- create FAQs

- use the News Forum

- use e-books

- use graded discussions in the discussion forum to ensure that everyone is participating

- use narrated PowerPoints, they are easy, convenient, and can be accessed easily by students

- use a Weekly Q \& A email to enable students to post questions regarding that week's content

Technical improvements:

- use of Google Docs for group projects

- use documentaries accessed from NCLive or YouTube

- have all students a camera so it can be seen if they are present

- somehow monitor if they are engaging in other activities such as texting or checking email during class

Finally, some insightful discussion from the survey:

"Without regular interaction with students it is hard to determine what tools enhance student success. This is the real challenge with online. Different students respond and/or need different tools to flourish. It is much easier in a live setting to customize techniques and practices based on student reaction than through online. In the end, it takes a very specific type of person to really maximize learning through the online medium...unfortunately, most opt for online because they see it as the "easy" way out. How you combat this...I have no idea."

\section{SUMMARY AND CONCLUSIONS}

In this paper, we analyzed faculty best practices for online teaching based on a faculty survey, considering different factors such as colleges, and demographics such as gender, age, as well as their job title (tenure status: tenure, tenure-track or non-tenure, status: full-time or part-time), and previous online teaching experiences. The best practices discussed here were: for lecturing, assignments/examinations, communication, starting a class and attendance and participation. Based on our analysis and discussion above, the following detailed conclusions seem to be valid:

- Overall, the most preferred best practices are the same group of methods: Confirm syllabus, emails, tracking, self introduction, homework, discussion questions. These techniques seem to be independent of the different groups in the sense that there might be a slight change in the ranking of these techniques for the different groups examined here but these methods are the highest rated methods, and on average their order is as stated above in descending order. A similar argument can be made for the least preferred 
practices: there is a general pattern where the same group of methods seems to be the least preferred, regardless of the group distinctions: live project presentation, live lecture with video, recorded video lecture, live lecture with audio, proctored exams. While the dislike for "live" activities is aligned with our expectations as it would restrict the flexibility of online learning, it was surprising to see that recorded videos ranked relatively low as well. We believe that this may be the case for tow possible reasons: first, the faculty may be skeptical about the reliability of the technology, second, this creates an additional workload for the faculty as they need to record their own lectures and possibly need to learn the related software. We believe that this is an important concern of the faculty to address, since recorded lectures do increase the quality of lectures for the students. Some of our recommendations would be providing assistance to the faculty for recording, and creating more reliable lecture capture infrastructure perhaps by changing the technology and by deploying preventive maintenance strategies.

- Both female and male preferences follow similar pattern but in general females seem to rate online techniques higher than the males, except for the rating of take-home exams. Another observation that can be made is that females tend to have a slightly larger variation in their rankings between the most and least liked best practices than males. We believe that this may be related to teaching flexibility (in both time and location) being more important for females when raising a family. Online teaching makes it easier to work from home, as time management becomes also easer with asynchronous teaching.

- While the pattern for most commonly used best practices seems to be not very expressed between the age groups, the differences between the least used practices seem to be bigger among the age categories. In other words, the methods that the different age groups like the most are similar but their dislikes seem to vary more. Part-time teachers consistently gave higher scores on the majority of these practices and part-time employees valued phone discussions much higher than their full time counterparts. This is not so surprising, as quite a few part-time faculty are full-time employed in the industry thus they would prefer phone meetings/office hours rather than face-to-face interactions with extra commute to the campus. While there doesn't seem to be a big difference in the three tenure status categories, the general trend is that tenure-track faculty rate online practices higher than non-tenure track faculty. This result might have sounded surprising initially, but the root cause of this may be related to training on online teaching. As the part-time instructors usually work full time somewhere else, they usually do not spend much time on-campus. This may hinder their access to training and other campus resources which would make them more familiar with the online teaching infrastructure.

- Full-time lecturers seem to give lower scores than the others for the majority of these methods. For teachers with previous participation in an online class the preference is strong for best practices such as confirm syllabus, emails, tracking, self introduction, HW, DQs, calendar and Q/A forum if they have participated in an online class before. Those faculty who took an online class, seem to also value more the audio lecture recording while not prefer take home exams. A general pattern is that the more experience, the higher the scores given for the best practices seems to be the case but it is a pattern that has a couple of exceptions.

- Regarding training: in general, having training makes the teachers give higher scores for all the best practices with the exception for notes and quizzes instructors have taken prior 
online classes, they seem to like the most popular techniques more and dislike the least popular techniques more as well.

- Mostly on-campus teachers have the lowest preferences for most of these techniques but unlike all the other teachers, they really seem to like take home exams. Teachers of graduate classes seem to have higher values for almost all the categories than teachers of undergraduate or both graduate + undergraduate classes. It is, however, not the case for quizzes (these are more important in undergraduate classes than in graduate classes), and proctored exams (lower ratings by graduate teaching instructors than undergraduate teaching only).These results are expected since graduate students are typically full-time employed and need flexibility. In addition, graduate students are typically more mature and can handle take home exams much better than undergraduate students. For this reason, proctored exams/quizzes are less desired for graduate students.

We would like to indicate that the best practices discussed here can help establishing a new online program as well as improving existing ones. While there are differences among departments and colleges in terms preference of these best practices, as detailed above there are common preferences across the board as well. It is recommended to combine these faculty preferences with the ones of the students (customers) to identify the best online learning and delivery environment for a degree program.

\section{References}

[1] Ozelkan, E. C. and Galambosi A., (2011) Perception and Preferences of Faculty for Online Learning, Proceedings of the American Society for Engineering Education (ASEE) Annual Conf. \& Exposition, Vancouver, Canada, June 26-29, 2011.

[2] Ozelkan, E. C. and Galambosi A., (2012) Overcoming Communication Barriers in Online Teaching: Understanding Faculty Preferences, Proceedings of the International Conference on Communication, Media, Technology and Design, Istanbul, Turkey, May 9-11.

[3] Bender, T., (2003) Discussion-Based Online Teaching to Enhance Student Learning, Theory, Practice and Assessment, Stylus Publishing, Sterling, VA

[4] Vonderwell, S. Liang, X and Alderman, K., (2007), Asynchronous Discussions and Assessment in Online Learning, Journal of Research on Technology in Education, 3P(3), 309, 328.

[5] Gilbert, P. K., \& Dabbagh, N., (2005). How to structure online discussions for a meaningful discourse: A case study. British Journal of Educational Technology, 36(1), 5-18.

[6] Wang, M., (2007) Designing online courses that effectively engage learnersfrom diverse cultural background, British Journal of Educational Technology, 38(2), 294-311

[7] Gahungu, A., Dereshiwsky, M. and Moan, E., (2006), Finally I Can Be with my Students 24/7, Individually and In Group: A Survey of Faculty Teaching Online, Journal of Interactive Online Learning, 5(2), 118-142.

[8] Dennen, V.P., Darabi, A.A., and Smith, L.J., (2007), Instructor-Learner Interaction in Online Courses: The relative perceived importance of particular instructor actions on performance and satisfaction, Distance Education, 28(1), 65-79 